\title{
Validation of Milk Product Pasteurization by Alkaline Phosphatase Activity
}

\author{
Hilal Ahmad Punoo* \\ Department of Food Science and Technology, University of Kashmir Hazratbal, India
}

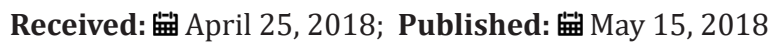

*Corresponding author: Hilal Ahmad Punoo, Department of Food Science and Technology, University of Kashmir Hazratbal Srinagar Kashmir J\&K, India

\begin{abstract}
The standard practices for indirectly assessing the pasteurization status of milk products are primarily based on the thermal in activation kinetics of the endogenous milk enzyme, alkaline Phosphatase (ALP).This review provides an invaluable, tool for both regulatory and in house process control and validation. Endogenous milk ALP manifests a slightly higher heat resistance than the pathogenic micro flora upon which pasteurization time and temperature requirements are based. Therefore, ALP activity is recognized and accepted as the method of choice for the rapid validation of milk product pasteurization. However, ALP assays have notable limitations that must be understood if they are to be administered and interpreted correctly and the results are to be applied judiciously. Issues such as the reactivation of heat denatured ALP and the presence of both heat stable and labile microbial ALP are addressed. A discussion of ALP in the milk of non-bovine speciesis presented based on the limited literature available. Also brief discussion of research involving alternative pasteurization indicators is presented. This review article is intended to summarize the pertinent details of the ALP assay for dairy products (considering the basis and limitations of various methods) and the processing, handling, and known compositional factors that influence the assay results.
\end{abstract}

Keywords: Pasteurization; Alkaline Phosphatase Assay; Validation; Atalkaline pH; Bovine Milk; Lipid Water; Colori Metric Assays; $\gamma$-Glut Amyl; Denaturation; Rutgers Phosphatase Test

\section{Introduction}

The vast majority of milk products are subjected to a definitive thermal treatment (i.e., pasteurization). Knowing the complexities of modern milk processing equipment global distribution systems, and increasing regulatory and industry demands, the alkaline Phosphatase (ALP) test has been adopted by many countries as the standard assay for rapid validation of the milk pasteurization process. The fundamental of the ALP test is based on the thermal inactivation characteristics of the ALP enzyme endogenous to milk. In short, ALP is slightly more resistant to thermal inactivation than target bacterial pathogens (namely Coxiellaburnetii and Mycobacterium tuberculosis, the most heat resistant bacteria present in milk) therefore, if ALP activities are greatly reduced, one can infer that the target bacterial pathogen population was at least similarly reduced and the legal thermal requirements for pasteurization were met. The detection of elevated ALP activity levels is primarily interpreted as an indication that either the milk

was not sufficiently pasteurized or was contaminated with raw milk post pasteurization (Harding [1]). The other interpretations of elevated ALP activities in finished products include the presence of bacterial ALP or the bio chemical reactivation of the ALP enzyme. Also contamination of pasteurized product with raw product has historically occurred as the result of pasteurization equipment failure, operator error, or mismanagement of raw and finished product disposition. Although the ALP assay is widely used and recognized as the most appropriate method for verifying milk pasteurization, some studies have raised concerns over the ability of this test to validate pasteurization under certain circumstances. The prudent application of ALP based assays must be based on an understanding of the assay and its limitations. Several different standard protocols exist for conducting ALP assays, each based on different sample preparatory methods or ALP substrate. Few comprehensive reviews report currently used assay technologies. 
To that end, this paper will review the relevant details of the ALP assay for milk product pasteurization process verification.

\section{Alkaline Phosphatase}

Alkaline phosphatase is a protein that was first described by Suzuki [2]. It is abundantly present in nature and found in many human body tissues, such a sliver, kidney, bone and blood cells. It is found in milk (Shakeel-Ur Rehman et al. [3] and other bodily fluids from many organisms at varying levels. Alkaline Phosphatase (EC3.1.3.1) is a membrane-bound glycol protein with sialic acid as sugar moiety. It is a phospho-monoesterase enzyme that catalyzes the hydrolysis of monoesters of phosphoric acid (atalkaline $\mathrm{pH}$ ), yielding phosphate and the corresponding alcohol. The abundance in nature and importance of this enzyme in biological systems has made ALP activity assessments one of the most common leper formed enzymatic tests (Miggiano [4]. Alkaline phosphataseis 1 of over 60 endogenous enzymes in raw bovine milk (Schlimme [5]). The structure of ALP from Escherichiacoli has been completely elucidated; however, mammalian ALP is known to have low A Sequence identity to ALP from E. Coli (Bortolato [6]). Purified bovine ALP was found to have a molecular mass of $187 \mathrm{k}$ Da and an iso electric point ranging from $\mathrm{pH} 5.4$ to 6.0 (Vega Warner [7]). It has maximal activity in the $\mathrm{pH}$ range 9.65 to 10.1 at $37^{\circ} \mathrm{C}$. In its active form, the bovine ALP molecule forms complexes with zinc atoms that impart structural integrity and functional properties. The presence of metal ions is also believed to have a role in the ability of bovine ALP to regain enzymatic activity after thermal inactivation (Wright and Tramer [8]). Bovine milk ALP is reported to be insoluble in fat and it is found in the lipid water inter face in milk. Alkaline Phosphatase is associated with the milk fat globule membrane (MFGM) in raw milk (Kosikowski [9]), which may be a consideration when concentrated or fractionated milk products, enriched in MFGM, are pasteurized. The breed of cow, volume of milk produced and stage of lactation (Haab and Smith [10] Murthy [11]) can influence the concentration of ALP in milk; however, earlier studies have demonstrated that the level of ALP in pooled milk is relatively constant (Burgwald [12]). Given the challenges with ALP as a marker enzyme some studies have examined other possible enzymes such as a denosinede aminase (EC3.5.4.4) (Martin [13] Schlimme [14]) and $\gamma$-glut amyl transferase (EC2.3.2.2) (dos Anjos [15]). The importance of bovine ALP to the dairy industry is related to it's the malign activation properties. Because it is slightly more resistant to thermal treatment than the bacterial pathogens on which validated pasteurization processes are based, the thermal inactivation of milk ALP correlates well with thermally induced bacterial death (van Bever [16]). Such correlations have established and strengthened the hypothesis that the ALP assay could be used as a criterion for pasteurization verification (Sanders and Sager [17]). More recent work also has found similar correlations comparing the inactivation responses of Salmonella senftenberg and Listeri amono cytogenes (Eckner [18]). The thermal inactivation of ALP has been found to follow first order kinetics, and the denaturation midpoint for milk ALP has been obtained at $56^{\circ} \mathrm{C}$ for a 30min heating. Indigenous milk ALP also can be inactivated by high pressure processing in the range 400 to $800 \mathrm{MPa}$ and at temperatures ranging from 5 and $40{ }^{\circ} \mathrm{C}$ (Rademacher and Hinrichs [19]). It has been reported that ALP inactivation induced by high pressure homogenization is due to mechanical forces such as shear, cavitation, and impact (Picart [20]). Pulse delectric field treatment can affect the inactivation of both the bovine and microbial ALP present in raw skim milk (Shamsi [21]). Also, predictive equations based on the inactivation of ALP in a pilot-plant HTST pasteurizer have been developed to assess the effectiveness of commercial pasteurization processes (McKellar [22]). Hence, assessment of ALP activity is used as a rapid, in direct indicator of pasteurization status in finished milk products.

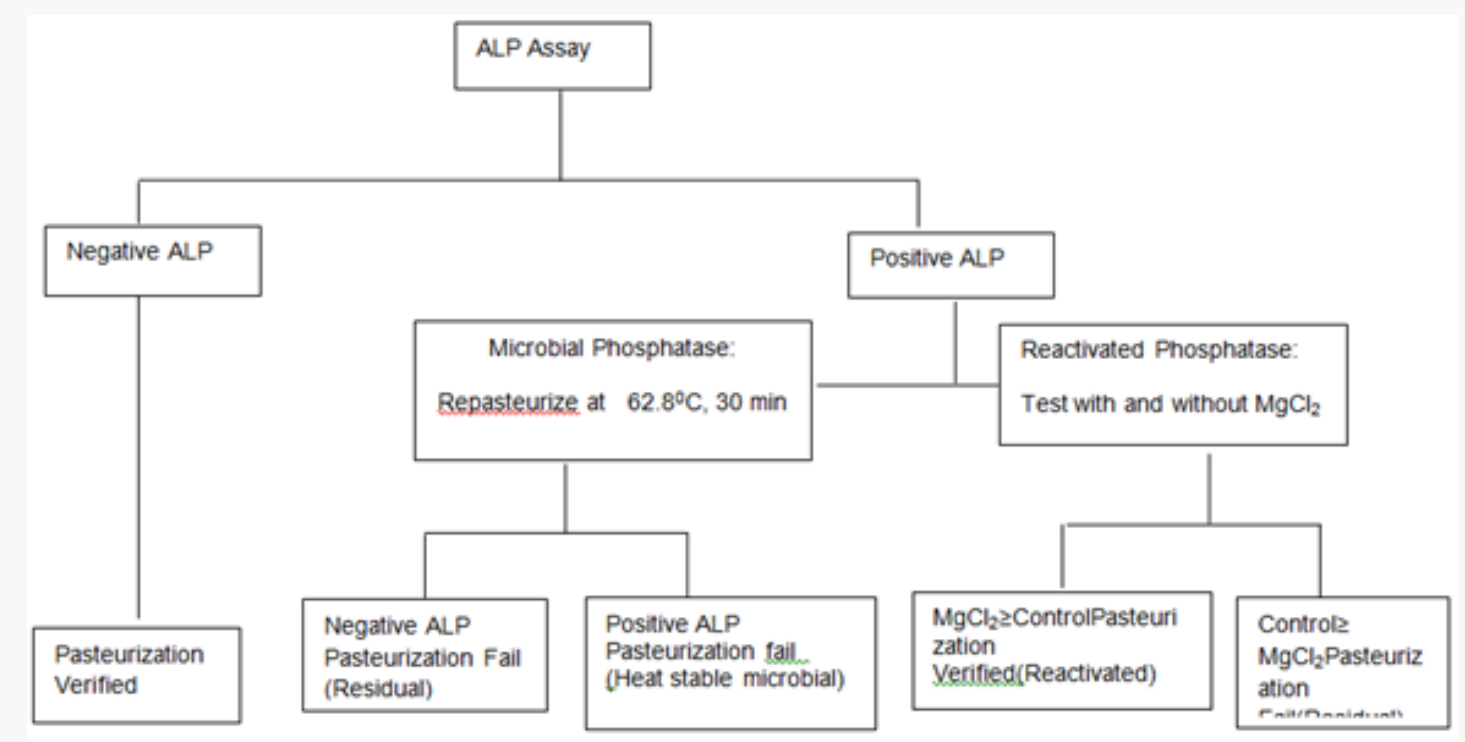

Figure 1: General logic to determine the pasteurization status of dairy products tested with the alkaline phosphate (ALP) assay. 


\section{Methods for ALP Measurement}

Assays employed to detect ALP activity can be broadly classified into 4types: colorimetric, fluorometric, chemilumine scent, and immunochemical methods. These methods have been adopted for use over many years; however, only the colorimetric, fluoro metric, and Chemiluminescent types have been recognized as validated methods for pasteurization verification in the dairy industry. Such recognition or acceptance is based on assay performances crutiny by various regulatory agencies, trade organizations, and academic institutions. Some concern exists about these different tests with regard to their status as validated ALP assays. For instance, the grade "A" Pasteurized Milk Ordinance (PMO; DHHS-FDA, 2007) states that an ALP assay must be done by an electronic procedure; the ordinance lists a fluoro metric and chemiluminescent method, but then describes the colorimetric reaction and finally refers the reader to a text (Rocco [23]) with numerous assays, both visual and electronic. The European Commission standards (2007) reference a fluoro metric method International Organization for Standardization 118161 as the approved testing means, yet also denote conditions for alternative methods and the need for ongoing work in areas including non bovine milk and non fluid milk products. A general procedure followed for the assay of milk for ALP activity is shown as a flowchart in Figure 1. For all of the above mentioned assays, it is necessary to run positive and negative controls and to closely follow the method procedures (Figure 1).

\section{Colorimetric Assays}

The earliest ALP assays were based on the use of reactions capable of generating chromo genic products. Most current colorimetric tests are based on the first Phosphatase test Kay and Graham [24]. Colorimetric assays are still present as a means of testing Rocco [23]. In these tests, phenol is liberated from di sodium phenyl phosphate substrate and reacted with a color forming reagent. As light improvement insensitivity based on the use of added standards was achieved with the development of the Gilcreas method. However, these early assays have limited sensitivity and require 18 to $24 \mathrm{~h}$ to conduct. For improved accuracy and to reduce the assay time, several other tests have been developed. The specific advantages and disadvantages of those methods are detailed below.

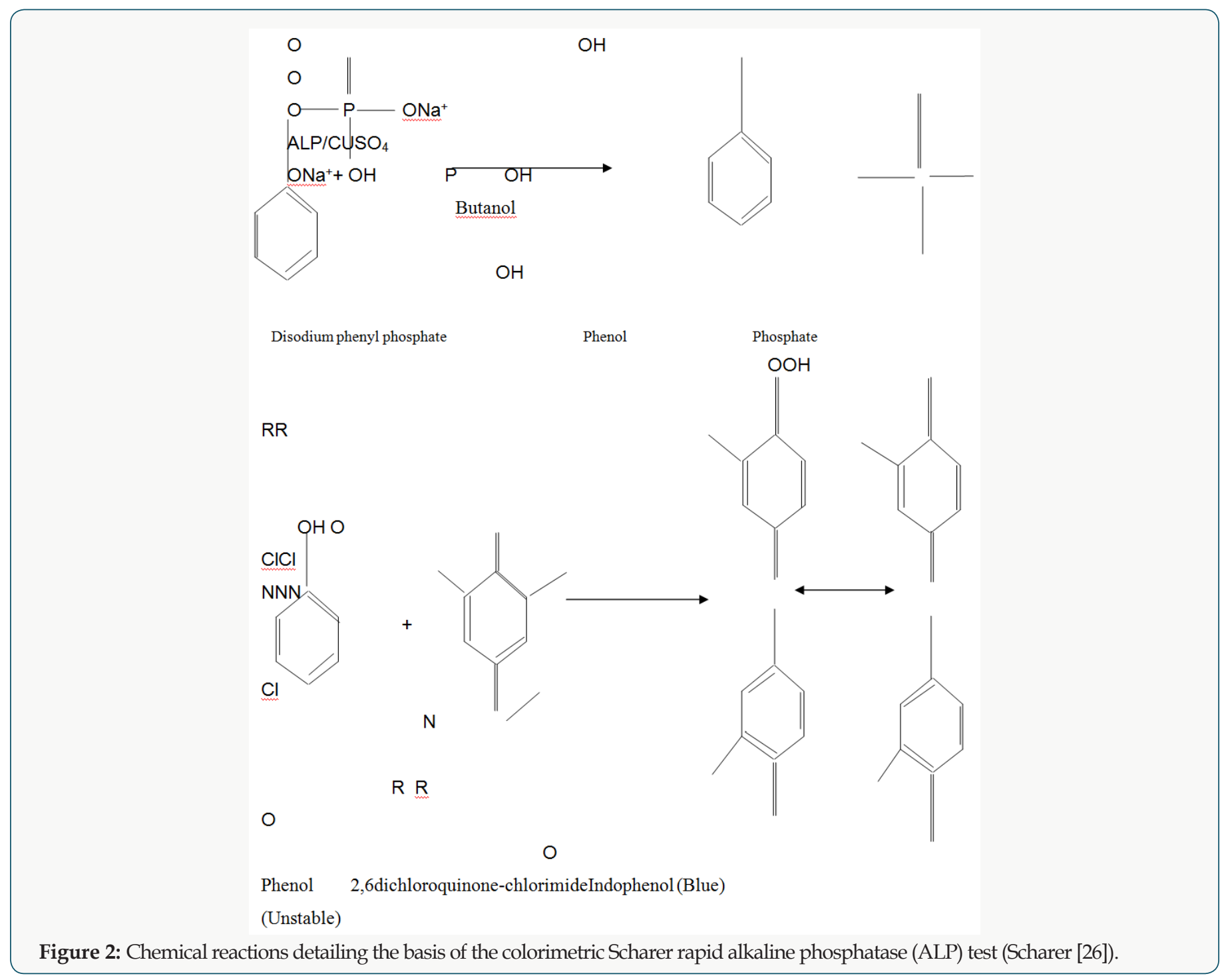




\section{Scharer Rapid Phosphatase Test}

Scharer's rapid Phosphatase test Scharer [25] is based on the original Kay and Graham [24] method, but offers a substantial reduction in analysis time $(\sim 75 \mathrm{~min})$. In short, ALP enzymatically cleaves a phosphate group from added di sodium phenyl phosphate substrate. The released phenol group is extracted with butanol and then reacted with 2,6-dichloroquinonechlorimidetoformindophenol,a blue color compound (Figure2). Under the controlled conditions of this assay increased ALP activity in the milk sample results in the generation of an increasingly intense blue color. The intensity of the blue is compared visually against asset of standard so read instrumentally with a spectro photo meter. The results are expressed as micrograms of phenol per milliliter of milk. The Scharer method Scharer [26] has several weaknesses limiting its application and wide acceptance. First, the possibilities of phenol contamination from improperly cleaned glass ware or from flavorants such as vanillin result in false positive assessments. To address this issue, Murthy [11] published several specific methods for glass ware and utensils election and cleaning. Second, the necessary reagents, as well as the formed in do phenol chromagen, are unstable overtime, resulting in an increased rate off alse negatives Scharer [26]. Although rapid, in expensive and convenient, Scharer's rapid Phosphatase test relieson subjective visual assessments of color development and is especially unreliable near the limit of detection or with colored product. A more objective method, based on spectro photo metric readings, has been proposed to confirm positive samples Murthy [11] and has been reported to be capable of detecting approximately 0.1 to $0.2 \%$ contamination by raw milk in pasteurized milk Angelino [27]. Given the high patho genicity and virulence of certain milk borne human patho gens, this relatively high limit of detection may be considered in adequate from a food safety perspective. In fact, the 2009 USFDAPMO specifically excludes the use of ALP assays with a limit of detection of greater than $350 \mathrm{mU} / \mathrm{L}$, such as the Scharer rapid test. A few modifications for improved precision have been developed, as detailed below (Figure 2). Rutgers Phosphatase Test, the use of butanol to extract the liberated phenol before the generation of color when using Scharer's test often results in the formation of an emulsion and reduces the efficiency of the extraction. To alleviate this source of error, Babs on and Greeley [27] used phenolphthale in mono phosphate as the substrate. As ALP releases phenolphthalein, the concentration is then determined by titration with sodium hydroxide (Figure 3). Unlike the Scharer reagents, the phenolphthalein in mono phosphate substrate and its hydrolysis product are very stable over time and storage conditions typical for this assay (Figure 3).
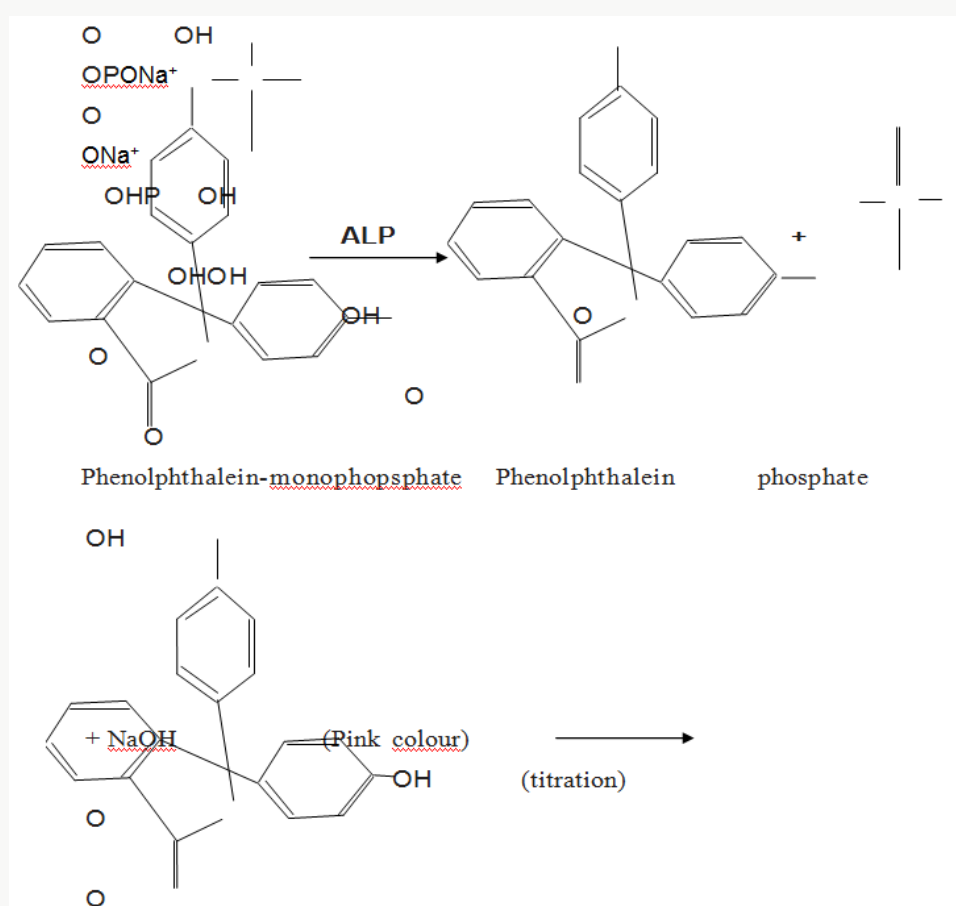

(titration)

Phenolphthalein

Figure 3: Chemical reactions detailing the basis of the colorimetric Rutgers alkaline phosphatase (ALP) test (Babson and Greeley [28]).

\section{Aschaffenburg and Mullen Test}

In this test, $\rho$-nitro phenyl phosphate is used as the substrate of the reaction and the development of a yellow color is used as an indicator of the liberated nitro phenol (Figure 4; A schaffenburg and Mullen [29]). This method is characterized as beings lightly more sensitive than the Kayand Graham method. Also, it does not require an extraction step or long incubation periods. This method is accepted under regulatory standards in the UK Rocco [23] [Figure 4]. 


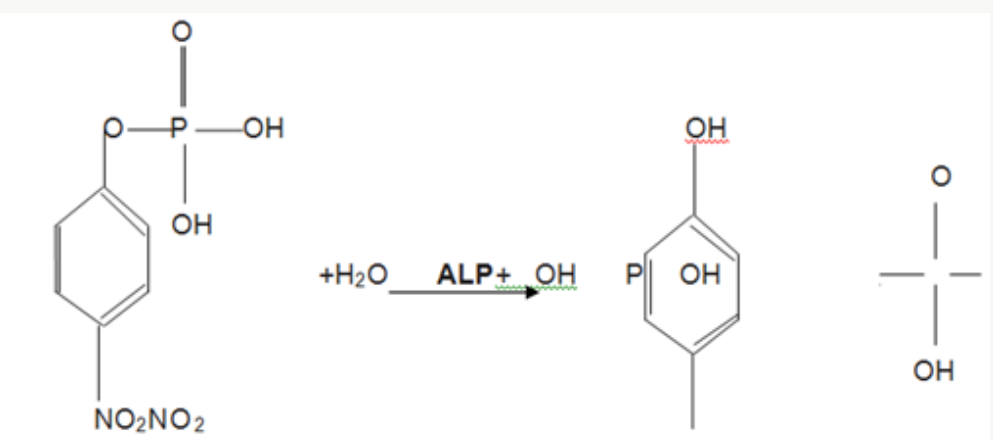

p-nitrophenylphosphateNitrophenyl Phosphate

(yellow colour)

Figure 4: Chemical reactions detailing the basis of the colorimetric Aschaffenburg and Mullen [54] alkaline phosphatase (ALP) test.

\section{Fluoro Metric and Chemiluminescent Assays}

The analytical methods based on the fluorescence properties of certain compounds are extensively used in the chemical and biological sciences, especially for enzymatic assays where improved sensitivity is needed. Fernley and Walker [30] published one of the first fluoro metric assays for bovine ALP. The fluoro metric assays are based on the ALP-mediated release of a phosphate radical from a self-indicating substrate, such as 4-methylum belliferyl phosphate, to form a highly fluorescent product, 7-hydroxy-4methyl-coumarin (4-methylumbelliferone), which has optimal fluorescence at $\mathrm{pH} 14$ Yoshitomi [31]. A mono phosphorylated benzothiazole derivative as the self indicating substrate also may be used for this reaction. Currently, a fluoro genicaromatic ortho phosphoric monoester (Fluorophos, Advanced Instruments Inc., Needham Heights, MA)is used for ALP assay in milk and milk products. In this assay, a fluorescent compound, "Fluoro yellow," is produced by hydrolysis of the Fluorophos substrate and then analyzed using a fluoro meter. The instrumental measurement of fluorescence generated overtime is correlated to enzymatic activity or the concentration of ALP. This specific fluorometric assay is reported to be much more rapid (reported at $3 \mathrm{~min}$ ) simple and about 100 to 1,000 times more sensitive than colorimetric assays such as the Scharer method Fox and Kelly, [32]. As a result, this fluorometric assay is sufficiently sensitive to detect even small irregularities during milk processing Rocco [23]. An alternative fluorometric assay has been reported by Fenoll [33] forme assuring residual ALP activity in a wide variety of solid and liquid dairy products. The method is based on the ALP mediated hydrolysis of an on fluorescent substrate, tri fluoro methyl- $\beta$-um be lliferone phosphate, to its highly fluorescent phenolate product. The assay is performed in a reverse micellar medium composed of mixed buffer (2-amino-2-methyl-1-propanol buffer, $\mathrm{pH}$ 9.0, and borate buffer, $\mathrm{pH}$ 9.0) in dioctyl sodium sulfosuccinate/isooctane, at a temperature of $38^{\circ} \mathrm{C}$. The total test time is $450 \mathrm{~s}$ and the detection limits are 0.04 , 0.4 , and $0.22 \%$ (vol/vol) for raw milk, whole milk, chocolate milk, and butter, respectively Fenoll [33]. The sensitivity, linearity, and repeatability of the Fluoro phos system have been compared with the A Schaffenburg and Mullen and Scharer colorimetric procedures for ALP testing in milk with raw milk additions, purified bovine ALP additions, and different heat treatments. The Fluorophos method has been reported to have high precision and repeatability and is both faster and simpler to perform than the traditional colorimetric tests Payne and Wilbey [34]. Many international trade and regulatory agencies accept fluoro metric assays as are liable test of pasteurization effectiveness for numerous dairy products. Current reports have established that the level of sensitivity of fluoro metric assays is in the range of 0.003 to $0.006 \%$ raw milk contamination or about 25 to $50 \mathrm{mU} / \mathrm{L}$ of ALP Black [35], a substantial improvement over colorimetric methods, where sensitivity ranges from 0.1 to $0.5 \%$ Claeys [36]. A fluoro metric method is approved by FDA, NCIMS, AOAC International, the International Association for Standardization, and the International Dairy Federation, and is listed in the PMO. Chemiluminescence is the basis for yet another approach to measuring ALP activity. Chemiluminescent assays for ALP analysis are based on the ALP-mediated de phosphorylation of adamantly1,2-dioxetansubstrates (e.g.,adamantyl-1,2-dioxetane phenyl phosphate). This class of substrates is specifically recognized and cleaved by ALP to yield a phenoxide intermediate, which decomposes with the emission of a prolonged low of light that can be read with alumino meter or refrigerated photoncounting device. This methodology provides a simple one reagent assay with a limit of detection of 1zmol (603molecules) of enzyme Kricka [37]. A chemiluminescent assay with sensitivities and assay times similar to the fluorescent methods was developed to determine the concentration of ALP in milk by Girotti [38]. The results agreed with those obtained by qualitative and quantitative absorption spectrometry for ALP, and the chemiluminescent method gave quantitative results without laborious solution and sample preparation. A chemiluminescent assay (Paslite, Charm Sciences Inc., Lawrence, MA) was reviewed and approved by FDA/ NCIMS and the International Association for Standardization/ International Dairy Federation (IS022160/IDF209) and is a long 
with the fluorometric test, 1 of the 2 technologies specifically noted in the 2009 PMO as acceptable for ALP testing in grade A milk products. An additional rapid chemiluminescent method also has gained validation from NCIMS in 2009 as an approved ALP assay. Referred to as the Fast Alkaline Phosphatase test (Charm Sciences Inc., Lawrence, MA), it is reported to have a limit of detection of $20 \mathrm{mU} / \mathrm{L}$ of ALP activity in HTST milk. This rapid assay requires minimal sample size and preparation and is reported to have a response time of $45 \mathrm{~s}$.

\section{Limitation of ALP Assays}

The ALP assay is affected by many factors, such as the composition of the product being tested, the ability of ALP to regain activity, and the presence of microbial ALP. The following topics are presented to detail the possible areas of concern when conducting or applying the results of the ALP assay.

\section{Compositional Factors}

Several studies have shown that milk or milk product composition can affect ALP assays. Painter and Bradley [39] performed ALP assays on milk and cream treated with various time and temperature conditions to determine ALP stability using a fluoro metric method. This study demonstrated that increasing fat levels resulted in an increased residual ALP activity. The ALP in milk is reported to be associated with the MFGM and concentrated in the creamphase (Kosikowski [9]). Products with elevated milk fat levels can have higher initial ALP values. Residual ALP values in non fat milk are reported to be approximately $50 \%$ lower than in whole milk when pasteurized at minimal HTST time and temperature requirements (Painter and Bradley [39]). Claeys [36] reported that although whole milk exhibits higher initial ALP activities than non fat milk, the fat content might not be the sole factor that influences the result of pasteurized milk ALP test.

\section{Interfering Compounds and Conditions}

Colored dairy products, such as strawberry milk, pose an obvious interference challenge with colorimetric ALP assays. Other non pigmented food additives with reactive phenolic groups, such as vanillin (when oxidized to vanillic acid), $\rho$-hydroxy benzoic acid and salicylic acid, can interfere with the ALP assay substrate yielding false positive results (Murthy [11]). Antibiotic residues of oxytetra cycline and penicillin with phenolic moieties have been shown to give false positive results with colorimetric tests Manolkidis [40]. Similar observations have been found with pesticides containing poly chlorinated biphenyls, due to the reactivity of phenyl groups Kumar [41]. Alkaline Phosphatase activity has been shown to be inhibited by flavonoids, saccharides Kuzuya [42], and as corbic acid Miggiano et al. [4]. Some poly phenolic compounds present in cocoa also are thought to have an inhibitory effecton ALP Murthy [11]. Sodium chloride $(0.25 \mathrm{M})$ is shown to reduce the thermal stability of ALP by approximately 50\% Linden [43]. Conversely, increased lactose concentration increases the thermal stability of ALP Sanders
[44]. The ALP enzyme can undergo an irreversible loss of activity at acidic pH values typical of cultured milk and yogurt (Murthy [11]). Recently in another study Ma [45] carbondioxide in corporate in dairy products for shelf life purpose shad no significant effect on ALP activity. The use of proper controls for interfering substances, along with negative and positive control for such fortified products, is generally advised.

\section{Methodology}

As with most standard protocols, certain conditions may limit the accuracy and precision of all ALP assays. Each method should be administered with utmost attention to standard protocol. A negative control (a sample heated to $95^{\circ} \mathrm{C}$ for $1 \mathrm{~min}$ followed by rapid cooling) can be included to determine the effect of contamination from glassware, reagents, coloring materials, fat, and soon. A positive control ensures the performance of reagents and that the test is working properly Murthy [46]; Murthy [47]. A portion of the negative control is mixed with 0.001 to $0.2 \%$ (based on sensitivity)of mixed herd fresh raw milk. In certain cases, aldose-response curve is obtained to test the lower detection limit of raw milk contamination. However, expressing the sensitivity of the method in this fashion is questionable as the ALP activity of raw milk varies greatly (from 119 to $4,380 \mu$ g of phenol/ $0.5 \mathrm{~mL}$ of milk) depending on factors that include the stage of lactation and animal health Haab and Smith [10].

\section{Microbial Alkaline Phosphatase}

Alkaline Phosphatase is produced by many bacterial strains and, in many cases, exhibits a higher thermal stability than bovine ALP, potentially increasing the incidence off ales positive results.So meofthereportstodatesuggestthatcertainbacterialcellsproducehe at-labile ALP, making it difficult to differentiate from residual bovine ALP Knight and Fryer [48]. Routine assays discussed above cannot directly distinguish between microbial or bovine ALP activity. As a result, the American Public Health Association recommends the re pasteurization of any positive sample. If the ALP activity of the re pasteurized sample is not noticeably reduced, it can be concluded that the original ALP assay result was due to the presence of heat stable microbial ALP. Murthy and Kaylor [49] suggested that because microbes can produce both heat labile and heat stable ALP, differentiating bovine and microbial ALP becomes especially problematic. Murthy and Kaylor [49] recommend us in gagarose-g elelectro phoresis to differentiate between microbial and bovine ALP. Psychrotrophic counts in raw milk before pasteurization of more than $1.2 \times 107 \mathrm{cfu} / \mathrm{mL}$ can have sufficient microbial ALP to cause a positive ALP test (Knight and Fryer [48]). However, the current practices used to discriminate between such activities are based on the characteristic individual inactivation temperature of the reactivated and microbial ALP [Figure1].Rosenthal [50] reported that cheeses inoculated with the mold Penicillium roquefortimanifestentirely heat-labile ALP activity. 


\section{Nonbovine Milk Products}

Whereas most studies on ALP detection have been conducted on cow milk, few have focused on non bovine milk and milk products Harding and Garry [51]; Moatsou [52].Although non bovine dairy foods remain a relatively small market, the need remains to validate non bovine dairy food pasteurization and understand the associated ALP ac-tivity. Many regulatory and industry entities recognize the utility of ALP assays for non bovine milk based on the performance history of such assays, rather than a substantial research foundation. Limited literature is available to provide such foundational data for the application of ALP assays in milk products of non bovine origin. Growing markets for such specialty dairy foods containing goat, sheep, or buffalo milk may increase the research attention to this area. Particular areas in need of scrutiny included enaturation kinetics and potential reactivation rates in non bovine milk. A brief treatment of known literature is included below. In general, goat milk has lower ALP activities when compared with cow milk Mathur [53]; Williams [54]. The ALP activity in sheep milk has been reported to be 2 or 3 times higher than that of cow milk and increases throughout lactation Scintu [55], from around 8,000 to $17,000 \mu \mathrm{g}$ of phenol/mL (Klotz [56]). Raynal Ljutovaca [57] reported considerable variations in ALP contents between species, breed within species and individual animals. The ranges of ALP concentrations in goat, sheep and cow milk found by the authors were 115 to 1,$300 ; 8,300$ to17,300; and1,800 to 4,750 $\mu$ g of phenol/ $\mathrm{mL}$, respectively and were apparently unrelated to the fat content of the milk samples. During the heat treatment of milks, more of the ALP activity in goat and sheep milks decreased compared with the ALP activity in cow milk Vamvakaki [58]. Some reports also suggest that ALP in sheep milk is slightly more sensitive to thermal denaturation than that in cow milk Anifan-takis and Rosakis [59]. As such, some colorimetric methods have a substantially reduced sensitivity and have been shown to have a substantial failure at eat even $0.8 \%$ added raw milk levels. Williams and Nottingham [60] modified the Aschaffenburg and Mullen assay procedure by increasing the sample volume and thus increasing the sensitivity for application to goat's milk. The ALP values in goat milk have been reported to vary widely with little or no correlation to milk fat,milk solids non fat, and yield with a minimal seasonal effect Williams and Nottingham [60]. Barbosa [61] suggested that the differences in the fat content of goat and sheep milks used for direct human consumption or cheese making have an effect on the performance of the ALP tests available. Klotz [56] determined and compared assays including colorimetric and fluoro-metric assays for ALP activity in goat and sheep milks to investigate the adequacy of current ALP standards. Klotz [56] concluded that fluoro metric assay was more sensitive and repeatable compared with the colorimetric assay for ALP activity in goat and sheep milks. Although only limited work has been done on many non bovine milk sources, fewer studies have been conducted on buffalo milk than on goat and sheep milks. One study of buffalo milk demonstrated that ALP activity is generally slightly less relative to bovine milk and reactivation rates are similar to cow milk Sharma and Ganguli [62]. Lombardi [63] evaluated the activities and rates of inactivation of ALP in raw buffalo milk and found that at $60{ }^{\circ} \mathrm{C}$, ALP showed the highest sensitivity to heat in activation, and at $70{ }^{\circ} \mathrm{C}$, ALP was completely in activated. Sharma [64] reported that the activity of the ALP enzyme in goat milk was significantly lower than in bovine or buffalo milks. They found no significant difference in ALP activities in milks from bovine and buffalo and observed that ALP activities were concentrated in creamphase. The authors also reported that the thermal in activation pattern of individual enzymes from bovine, buffalo and goat milks was similar. A study was conducted by the International Dairy Federation and the International Organization for Standardization to evaluate the reproducibility of a chemilumine scent method for ALP at $50,100,350$, and $500 \mathrm{mU} / \mathrm{mL}$ in the whole milk of multiple species to meet new regulations in the US and proposed regulations in the EC. Fifteen laboratories from 8 countries evaluated bovine, goat, sheep and buffalo milks; bovine skim milk; $20 \%$ fat cream; and $2 \%$ fat chocolate milk. The results of this study revealed that the method was comparable to the fluorometric assays in performance and indicating that the chemiluminescent method is suitable for measuring ALP in the milk of multiple species and in fluid dairy products at the US and EU levels of $<350 \mathrm{mU} / \mathrm{mL}$ Salter and Fitchen [65]). In addition, Wernery [66] found that ALP cannot be used to evaluate the correct pasteurization of camel's milk as considerably greater temperatures are required to destroy ALP in camel's milk compared with ALP in cow 's milk. The authors suggest the use of other enzymes such as lactoperoxidase (POD) or $\gamma$ glutamyl transfer as e as more suitable markers for the pasteurization of camel's milk. Similarly, it was observed that ALP is not a suitable indicative marker for confirmation of dromedary milk pasteurization as it is not inactivated at $72^{\circ} \mathrm{C}$, the accepted temperature for HTST pasteurization of other milks. $\Gamma$ Glutamyl transfer as e has also been proposed by Wernery [67] as a possible candidate for the evaluation of drome diary milk pasteurization.

Non fluid Dairy Products. Several other dairy products, such as butter and cheese, can be evaluated for pasteurization status using an ALP assay. The literature cites many modified methods to suit certain specific products such as colored milks (Kwee [68]), flavored milks (International Dairy Federation, 1999) and other products, some of which are detailed below. Due to the established micro flora, processing parameters, and matrix effects, the ALP activity assessment in cheese is more complicated. Because many microbes can produce ALP, ripened and aged cheeses with increased micro flora can yield a positive ALP test. Alkaline phosphatase is also reported to have a potential role in cheese ripening ShakeelUr-Rehman [69]. Time, temperature, and pH during cheese making are found to influence the denaturation of ALP Battistotti [70]. The ALP assays are considered able to detect cheese made from unpasteurized milk regard less of cheese age, provided that proper controls are in place. A control test was devised that consisted of cheeses amplere pasteurization at 62.8 or $66{ }^{\circ} \mathrm{C}$ for $30 \mathrm{~min}$ (American Public Health Association method) to distinguish 
microbial and reactivated ALP. Pratt Lowe [71] argued that because certain Mexican-style cheeses may have both heat-labile and stable microbial ALP, the current ALP assay methods may be questionable for such products. A subsequent study Murthy and Cox [47] also argued that heat lability of microbial ALP could be due to the presence of salt, which may have a role in increasing the ALP stability in cheese. Additional studies with Mexican style PrattLowe [71] and blue veined cheeses Rosenthal [50] further questioned the ability of current methods to discriminate microbial and bovine ALP in cheese. Rosenthal [50] also reported that a raw milk Granaty pecheese showed negative ALP assay results; such a result was attributed to the handling of curds at hot temperatures $\left(55^{\circ} \mathrm{C}, 1 \mathrm{~h}\right)$ in mildly acidic whey. The curd handling effecton ALP also is noted in the ISO standard11816-2:2003.The polaro graphic method for ALP published by Lechner and Wolfseder also is considered for use in cheese produced with raw milk, but the activity should be at least $500 \mathrm{mU} / \mathrm{g}$. Most butter in the US is manufactured from fresh, pasteurized cream. A negative ALP activity test will result in such creams immediately after heating and cooling and when stored at temperatures below $4{ }^{\circ} \mathrm{C}$. However, butter is known to yield false positives due to reactivation when the pasteurized cream/butter is stored at higher than $4.4{ }^{\circ} \mathrm{C}$ for more than 24h Freeman [72]. Differentiating residual ALP from reactivated ALP is difficult for several reasons. Karmas and Kleyn [73] conducted a study on experimental and commercial butters to evaluate the different ALP activities (residual, microbial, and reactivated) using both the Official AOAC and Rutgers methods. Karmas and Kleyn [73] found that unsalted butter always exhibited ALP activity, where as the unsalted samples revealed very little or no activity. The AOAC method used by the authors, however, is unable to give information to distinguish between native, residual, and reactivated ALP activity. In alater study, the same authors stated that the AOAC method used to determine ALP was difficult to perform on butter due to the in appropriate incorporation of an aqueous Mg solution into solid water in oil emulsion. Preparing the butter to increase solubility may assist in the incorporation of $\mathrm{Mg}$, yet is not recommended when testing for reactivated ALP. It was concluded that the AOAC method was acceptable to determine ALP activity in butter, but it was unable to distinguish between native residual and reactivated ALP activity Karmas and Kleyn [73]. McKellar [22] examined and modified the AOAC methodology and developed techniques for sampling butter for ALP determination. Their results showed that melting butter at $40^{\circ} \mathrm{C}$ led to positive ALP reactions. The use of a cork borer to take a solid sample for analysis was an effective way to eliminate the reactivation of the enzyme during the analysis. Also, the addition of as little as 0.1m MEDTA to freshly pasteurized cream was reported to aid in minimizing the reactivation of ALP resulting from temperature abuse of the samples. The use of a high pH buffer (9.6) also helped in reducing the reactivation of the enzyme McKellar [22]. Little contemporary literature has been published regarding ALP activity in icecream and ice cream mix.In general, approaches to assaying icecream for
ALP include melting the product and allowing it to stand for $60 \mathrm{~min}$ to release air and inclusions such as nuts or candies. Despite the higher solid content, Hahn and Tracy [74] showed that added serum solids did not affect ALP inactivation. Conversely, Caulfield and Martin (1939) demonstrated that added sucrose had a protective effect against thermal ALP inactivation. However, given the higher minimum pasteurization times and temperatures for ice cream mix, this effect was considered in consequential. Presence of Iso enzymes. Iso enzymes or iso enzymes are variants of enzymes that catalyze the same reaction, but have differences in A Sequence and can be distinguished by techniques such as electrophoresis or iso electric focusing. Peer boom [75] identified 3 different forms or iso enzymes of ALP from raw bovine cream and milk, designating the $m \alpha-, \beta-$, and $\gamma$-ALP. Molecular weights of all 3 forms varied largely. During reactivation in pasteurized cream, only the $\beta$-isozyme was detected Peer boom [76], suggesting that the $\beta$-isozyme for misprimarily involved with the reactivation process. In alater theory on re naturation of ALP from pasteurized cream, Peer boom [77] suggested that a part of the lipo protein complex comprises the outer layer of the MFGM and includes the $\beta$ is enzyme ALP. During heat treatment, the $\beta$-isozyme migrates into the water phase as denaturation proceeds. Upon cooling, as the de naturated $\beta$-isozyme is rein corporate into the MFGM environment, it recovers enzymatic activity. There is, accordingly, a marked increase in $\beta$-isozyme content in the MFGM. Reactivation of Alkaline Phosphatase. Because the result of the ALP assay is considered indicative of the effectiveness of the milk pasteurization, the possibility of getting positive tests due to ALP reactivation also can be a problem when testing the activity of this enzyme in dairy products. Wright and Tramer [78] were the first to recognize ALP reactivation. They reported that pasteurized milk could test positive for ALP activity when stored at temperatures ranging from 22 to $37^{\circ} \mathrm{C}$, even when a negative ALP result was obtained for the same pasteurized milk following processing. Cream heated to as low as $74^{\circ} \mathrm{C}$ with subsequent to rage at $>30^{\circ} \mathrm{C}$ temperatures has also shown ALP reactivation Lyster and Aschaffenburg [79]. Murthy [46] conducted a series of experiments to demonstrate that the maximal reactivation of ALP in milk products occurred when heated to 104.4 ${ }^{\circ} \mathrm{C}$, incubated at $34{ }^{\circ} \mathrm{C}$, and adjusted to $\mathrm{pH}$ 6.5. They also found that raw milk subjected to rapid heating above $85^{\circ} \mathrm{C}$ is more susceptible to "reactivation or renaturation" of the ALP enzyme Wright and Tramer [78]. Subsequent research could not establish a correlation between reactivation, time/temperature of pasteurization, or post process storage time. It also was found that the propensity for reactivation varied in milk with no specific relationship to fat content, as corbic acid, or metalion content Wright and Tramer [78]. It has been concluded that milk pasteurized at temperatures higher than $71.7^{\circ} \mathrm{C}$ is more prone to reactivation. In another study, cream heated to as low as $74{ }^{\circ} \mathrm{C}$ with subsequent to rage at $>30^{\circ} \mathrm{C}$ temperatures showed reactivation Lyster and Aschaffenburg [79]. The role of metallic ions (e.g., magnesium acetate) in the reactivation of ALP has been the focus of several studies Richardson [80]; 
Kuzuya [42]. The reported results suggest that Mg2+ along with $\mathrm{Zn} 2+$ are stimulatory to ALP activity reactivation, where as Co2+,Cu2+, EDTA, and Sn2+ may inhibit ALP reactivation and reactivation depending on several factors such as the availability of free $\mathrm{Ca} 2+$ and $\mathrm{Mg} 2+$ ions, heating and storage conditions, availability of phosphates, and pH conditions Sharma and Ganguli [62]; Linden [81];Linden [43]; Murthy and Peeler[13]; Fox and Kelly [32]. It has been reported that the reactivation process is imminent in UHTtreated milk when stored at ambient temperature. Homogenization before heat treatment has been found to reduce the reactivation rate. In later work Painter and Bradley [39] found that milks with low fat content are slightly less susceptible to reactivation. Another study Gallusser and Bergner [82] showed the reactivation rate of ALP to have an inverse relationship with oxygen content; similarly, UHT milk with increased available oxygen showed less reactivation. It has been suggested that at high oxygen concentrations, the free sulfhydryl groups created during the heat treatment are later oxidized during storage, thus inhibiting sulfhydryl cross linking reactions critical for the structure dependent activity of ALP. Analytical steps to differentiate between residual and reactivated ALP are based on the premise that ALP will reactivate (4-to10-fold increase inactivity) in the presence of magnesium salts Richardson [80]. In such a situation, a finished pasteurized product may yield a false positive ALP assay. Whenever a false-positive test result is suspected due to reactivated ALP, the analyst should proceed according to the following assessments:(1) the milk in question is divided into 2 samples, treating 1 with a magnesium acetate solution to promote reactivation;(2) both samples are incubated at $34{ }^{\circ} \mathrm{C}$ for $60 \mathrm{~min}$; (3) the sample is diluted by 6-fold; and then (4) the sample is assayed for ALP activity. If the Mg-treated sample readings are equal to or higher than the control sample, the original ALP assay is considered as a result of reactivated ALP. Conversely, if the $\mathrm{Mg}$ treated sample exhibits less activity than the control, the values are considered to be resulting from residual ALP. Deciphering the difference between residual and reactivated ALP activity can pose a problem for plant and regulatory personnel. This problem may be further complicated by the presence of microbial ALP. Alternative Methods The limitations of currently adopted technologies and the diversity of dairy products has led to the development of alternative methods of residual ALP determination. Noted alternatives are listed below; however, adoption and application of these methods has yet to occur with most recognized regulatory bodies. Bios trip Technologies. Biostrips have grown in popularity as a means to diagnosis various diseases as well as for testing different chemical and bio chemical parameters. Sharma [83] developed a test using dry reagents trips for detection of ALP activity in milk. The test is based on ALP reaction with $p$ nitro phenyl phosphate in the presence of water to liberate $\rho$-nitrophenol and in organic phosphate. The $\rho$-nitrophenol substrate reacts with a specific chromo-gen that changes the color of the strip from light blue to green, which can be directly visualized. The strip method has a sensitivity of $>0.5 \mathrm{U} / \mathrm{L}$ and is stable at room temperature for several months. This method is proposed as an alternative for dairy industries and remote areas where expensive instruments are unavailable. Another system, the Reflect to quant strip rapid test, also has been used to measure the in activation of enzymes including ALP, lipase, and POD in milk. Martin [84] reported using it to differentiate between short time heated and high temperature heated milk through ALP and POD inactivation. This ALP assay requires $20 \mathrm{~min}$ incubation at $37{ }^{\circ} \mathrm{C}$ and has a measuring range of 1.0to10U/L. Electrochemical Assays. Alkaline Phosphatase activity can be determined electrochemically using an amperometric graphite Teflon compositety rosinase biosensor (Serra [85]). This electrochemical assay developed by Serra [85] is a rapid (5min) and highly sensitive $(6.7 \times 10-14 \mathrm{M}$ detection limit for ALP) test for the measurement of ALP activity, and it does not require an incubation step. In this assay, ALP activity is determined using phenyl phosphate as substrate, which is enzymatically de phosphorylated to form phenol. The phenol generated by the action of ALP is oxidized to quinine by immobilizedtyrosinase. At thetyrosinase composite electrode surface, quinine is reduced to cate cholth at is then reoxidized by tyrosinasetoquinone producing are doxcycle that produces the amplification of electro chemical signal obtained at the bio sensor and the sensitive detection of ALP Serra [85]; Fox and Kelly [32]. The use of 4-nitrophenyl phosphate as the substrate for a potential metric assessment of ALP in milk and dairy products has been described by Hassan [86] The sensor measures the decrease of a fixed concentration of 4-nitrophenylphosphate substrate as a function of the enzyme activity. This assay is reported to exhibit goods electivity and stability with a detection limit of $6.3 \times 10-6 \mathrm{M}$ over the $\mathrm{pH}$ range of 4.5to10.The results obtained were reported to agree fairly well with data obtained from spectrophoto metric methods.

\section{Conclusion}

Understandard conditions of assay, the ALP method has been shown to be are markably valuable tool for the routine assessment of milk pasteurization validation, yet some concerns still exist. Reactivation and microbial ALP still cause concern and regulatory difficulties especially for UHT processed products that are stored at room temperatures. Research has recently led to the reduction of the maximum residual limiting rade Aproducts to $350 \mathrm{mU} / \mathrm{L}$ (Painter and Bradley,[39]; International Dairy Federation,1999) found less than 150mU/Lof ALP activity in under pasteurized low fat milk. In a collaborative study with a fluorometric assay, Rocco [87] found that milk contaminated with as much as $0.5 \%$ raw milk showed less than $265 \mathrm{mU} / \mathrm{L}$ of ALP activity, there by stressing the need to reconsider current regulatory standards. An additional study (Klotz [56]) on cow, goat and sheep milks also suggests that the present limit of $350 \mathrm{mU} / \mathrm{L}$ can be reduced further given that raw goat milk ALP levels were $<350 \mathrm{mU} / \mathrm{L}$. The high sensitivity of the fluorometric and chemiluminescent methods has further motivated such consideration [88-94]. The most accurate ALP assay results are those done on product immediately after heat treatment, 
before storage time and microbial growth may allow extraneous ALP activities to appear (i.e.,0 time analysis).Non bovine milk ALP requires additional scrutiny. Much of the data reported on non bovine milks has yet to be thoroughly explored. Many of the recent studies have been conducted using technologies that are decade sold. Additionally, more fundamental details for the kinetics of ALP denaturation and reactivation rates have yet to be thoroughly described for non bovine species.

\section{References}

1. Harding F (1991) Alkaline phosphatase test as a measure of correct pasteurization. Bullet in 262 Int Dairy Fed, Brussels, Belgium.

2. Suzuki U, Yoshimura K, Takaishi M (1907) Ubereinenzym "phytase"dasanhydro-oxy-methylen-diphosphorsaurespaltet. Bull Coll Agric Tokyo Imp Univ 7: 503-512.

3. Shakeel Ur Rehman, Fleming CM , Farkye NY, Fox PF (2003) Indigenous phosphatases in milk. In. Advanced Dairy Chemistry, pp. 523-544.

4. Miggiano GA, A Mordente, GE Martorana, E Meucci and A Castelli (1983) In-vitro effect of ascorbicacid on bovine kidney alkaline phosphatase activity. ActaVitamin ol Enzymol 5(3): 153-158.

5. Schlimme E, Kiesner C, Lorenzen PC, Martin D (1997) Chemical process parameters for thermal inactivation of alkaline phosphatase in milk. Kieler Milchw Forsch 49(3): 207-219.

6. Bortolato MF, Besson, M Roux (2002) An infrared study of the thermal and $\mathrm{pH}$ stabilities of the GPI-alkaline phosphatase from bovine intestine. Biochem Biophys Res Commun 292(4): 874-879.

7. Vega-Warner AV, Wang CH, Smith DM, Ustunol Z (1999) Milk alkaline phosphatase purification and production of poly-clonal antibodies. J FoodSci 64(4): 601-605.

8. Wright RC, Tramer J (1956) Reactivation of milk phosphatase following heat treatment IV. The influence of certain metallic ions. J Dairy Res 23(2): 248-256.

9. Kosikowski FV (1988) Enzyme behavior and utilization in dairy technology. J Dairy Sci 71(3): 557-573.

10. Haab W, LM Smith (1956) Variations in alkaline phosphatase activity of milk. J Dairy Sci 39(12): 1644-1650.

11. Murthy GK, Kleyn DH, Ichardson TR, Rocco RM (1992) Alkaline phosphatase methods. Standard Methods for the Examination of Dairy Products. Am Publ Health Assoc Washington, USA.

12. Burgwald LH (1939) The phosphatase test. A review of the literature on its application for detecting irregularities in the pasteurization of milk and dairy products. J Dairy Sci 22(10): 853-872.

13. Murthy GK, Martin R, Rhea US, Peeler JT (1979) Rapid colorimetric test for alkaline phosphatase in dairy food products. J Food Prot 42(10): 794799.

14. Martin D, C Kiesner, PC Lorenzen, E Schlimme (1998) Adenosine deaminase (EC3.5.4.4.) Apotential indicator of heat treatment for the distinction of short-time and high-temperature pasteurized milk from the market. KielerMilchw Forsch 50: 225-233.

15. Anjosdos F, A Machado, C Ferro, F Otto, E Bogin (1998) Gamma-glutamy transferase as a marker for the pasteurization of milk. J Food Prot 61(8): 1057-1059.

16. VanBever AK (1943) The influence of temperature and pasteur-izing time upon the enzymes and bacteriain milk. Enzymologia 11: 7-18.

17. Sanders GP, Sager OS (1948) Heat inactivation milk phosphatase in dairy products. J Dairy Sci 31(10): 845-857.
18. Eckner KF (1992) Fluoro metric analysis of alkaline phosphatase in activation correlated to Salmonella and Listeria in activation. J Food Prot 55: 960-963.

19. Rademacher B , Hinrichs J (2006) Effects of high pressure treatment on indigenous enzymes in bovine milk: Reaction kinetics, inactivation and potential application. Int Dairy J 16(6): 655-661.

20. Picart LM, Thiebaud, Rene M, Guiraud JP, Cheftel JC, et al. (2006) Effects of high pressure homogenization of raw bovine milk on alkaline phosphatase and microbial inactivation. A comparison with continuous short-time thermal treatments. J Dairy Res 73(4): 454-463.

21. Shamsi K, Versteeg C, Sherkat F, Wan J (2008) Alkaline phosphatase and microbial inactivation by pulsed electric field in bovine milk. Innov Food Sci Emerg Technol 9(2): 217-223.

22. McKellar RC, HW Modler, H Couture, A Hughes, P Mayers, et al. (1994) Predictive modeling of alkaline-phosphatase in activation in a hightemperature short-time pasteurizer. J Food Prot 57: 424-430.

23. Rocco RM (2004) Standard Methods for the Examination of Dairy Products. In. Alkaline phosphatase methods. Wehrand HM, Frank JF American Public Health Association, Washington, USA.

24. Kay HD, WR Graham (1935) The phosphatase test for pasteurized milk. J Dairy Res 6: 191-203.

25. Scharer H (1938) A rapid phosphor monoesterase test for control of dairy pasteurization. J Dairy Sci 21: 21-34.

26. Scharer H (1943) Laboratory control of milk under war conditions. The rapid phosphatase test. Am J Public Health Nations Health 33(4): 396398

27. Angelino PD, GL Christen, MP Penfield, S Beattie (1999) Residual alkaline phosphatase activity in pasteurized milk heated to various temperatures measurement with the Fluorophos and Scharer rapid phosphatase tests. J Food Prot 62(1): 81-85.

28. Babson AL, SJ Greeley (1967) New substrate for alkaline phosphatase in milk. J Assoc Off Anal Chem 50: 555-557.

29. A schaffen burg R, JEC Mullen (1949) A rapid and simple phosphatase test for milk J DairyRes16(1): 58-67.

30. Fernley HN, PG Walker (1965) Kinetic behavior of calf -intestinal alkaline phosphatase with 4-methyl umbelliferyl phosphate. Bio chem J 97(1): 95-103.

31. Yoshitomi K (2004) Alkaline phosphatase activity in cheeses measured by fluorometry. Int J Food Sci Technol 39(3): 349-353.

32. Fox PF, AL Kelly (2006) Indigenous enzymes in milk:Over-view and historical aspects Part2. Int Dairy J 16(6): 517-532.

33. Fenoll J, G Jourquin, JM Kauffmann (2002) Fluorimetric de-termination of alkaline phosphatase in solid and fluid dairy products. Talanta 56(6): 1021-1026.

34. Payne C, Wilbey RA (2009) Alkaline phosphatase activity in pasteurized milk: A quantitative comparison of Fluorophos and colourimetric procedures. Int J Dairy Technol 62(3): 308-314.

35. Black RG, M Kuzyk, J Duggan (1993) Evaluation of afluorometric assay for alkaline phosphatase in fluid dairy products. Aust J Dairy Technol 47: 164-167.

36. Claeys WL, AM vanLoey, ME Hendrickz (2002) Kinetics of alkaline phosphatase and lacto peroxidase inactivation, and of $\beta$-lacto globulin denaturation in milk with different fat content. J Dairy Res 69(4): 541553.

37. Kricka LJ (2003) Clinical applications of chemiluminescence. Anal Chim Acta 500(2): 279-286 
38. Girotti S, E Ferri, S Ghini, R Budini, A Roda (1994) Chemiluminescent assay of alkaline phosphatase in milk. Neth Milk Dairy J 48(4): 213-224.

39. Painter CJ, Bradley RL (1997) Residual alkaline phosphatase activity in milks subjected to various time temperature treatments. J Food Prot 60: 525-530.

40. Manolkidis KS, E Alichanidis, AG Varvoglis (1971) Effects of some antibiotics on the milk phosphatase pasteurization test. J Dairy Sci 54(3): 335-338.

41. Kumar P, RK Sud, KG Gupta (1973) Interference of some pesticides in the milk phosphatase pasteurization test. J Dairy Sci 56(5): 553-557.

42. Kuzuya Y, Y Kanamaru, TT anahashi (1982) Purification of bovine milk alkaline phosphatase with affinity chromatography and effect of flavonoids and saccharides on the enzyme activities. Nippon Chikusan Gakkaiho 53(1): 45-49.

43. Linden G (1979) Biochemical study of some aspects of milk alkaline phosphatase reactivation. Milchwissen schaft 34: 329-332.

44. Sanders GP, Sager OS, Hupfer JA (1954) Factors affecting the sensitivity and accuracy of the phosphatase test. J Dairy Sci 37(6): 698-710.

45. Ma Y, DM Barbano, JH Hotch kiss, S Murphy, JM Lynch (2001) Impact of $\mathrm{CO}_{2}$ addition to milk on selected analytical testing methods. J Dairy Sci 84(9): 1959-1968.

46. Murthy GK, Cox S, Kalyor L (1976) Reactivation of alkaline phosphatase in ultra high temperature, short-time processed liquid milk products. J Dairy Sci 59(10): 1699-1710.

47. Murthy GK, Cox S (1988) Evaluation of APHA and AOAC methods for phosphatase in cheese. J Assoc Off Anal Chem 71(6): 1195-1199.

48. Knight AH, SM Fryer (1989) The development of heat resistant phosphatase activity in raw milk. J Soc Dairy Technol 42: 81-86.

49. Murthy GK, Kaylor LO (1990) Evaluation of APHA and AOAC II methods for phosphatase in butter and differentiation of milk and microbial phosphatase by agarose-gel electrophoresis. J Assoc off Anal Chem 73: 681-687.

50. Rosenthal I, Bernstein S, Rosen B (1996) Alkaline phosphatase activity in Penicillium roque forti and in blue-veined cheeses. J Dairy Sci 79(1): 16-19.

51. Harding F, E Garry (2005) Collaborative evaluation of a fluorometric method for measuring alkaline phosphatase activity in cow's, sheep's, and goat's milk. J Food Prot 68(5): 1047-1053.

52. Moatsou G (2010) Indigenous enzymatic activities in ovine and caprine milks. Int J Dairy Technol 63: 16-31.

53. Mathur MP (1974) Studies on alkaline phosphatase in goat milk. Indian J Dairy Sci 28: 145-147.

54. Williams DJ (1986) A modification to the Aschaffenburg and Mullen alkaline phosphatase test suitable for goat's milk. Aust J Dairy Technol 41: 28-30.

55. Scintu MF, Daga E, Ledda A (2000) Evaluation of spectropho tometric and fluorometric methods for alkaline phosphatase activity determination in ewe's milk. J Food Prot 63(9): 1258-1261.

56. Klotz V, A Hill, K Warriner, M Griffiths, J Odumeru (2008) Assessment of the colorimetric and fluorometric assays for alkaline phosphatase activity in cow's, goat's, and sheep'smilk. J Food Prot 71: 1884-1888.

57. Raynal Ljutovaca K, Park YW, Gaucheron F, Bouhallab S (2007) Heat stability and enzymatic modifications of goat and sheep milk. Small Rumin Res 68(1-2): 207-220.

58. Vamvakaki AN, Zoidou E, Moatsou G, Bokari M, Anifatakis E (2006) Residual alkaline phosphatase activity after heat treatment of ovine and caprine milk. Small Rumin Res 65(3): 237-241.
59. Anifantakis EM, PS Rosakis (1983) Alkaline phosphatase activity of sheep milk and some factors affecting it. Egyptian J DairySci 11: 173182.

60. Williams DJ, Nottingham SM (1990) Suitability of a modification to the Aschaffenburg and Mullen alkaline phosphatase test or goats'milk: Collaborative study. Aust J Dairy Technol 45(1): 21-23.

61. Barbosa M (2005) Interest in controlling alkaline phosphatase activ-ity in sheep and goat milks. Pp. 117-127.

62. Sharma RS, Ganguli N C (1974) Purification and properties of reactivated alkaline phosphatase from buffalo milk. Milchwis senschaft 29: 79-84.

63. Lombardi P, L Avallone, AD Angelo, TM, E Bogin (2000) Buffalo-milk enzyme levels, their sensitivity to heat inactivation, and their possible use as markers for pasteurization. J Food Prot 63(7): 970-973.

64. Sharma R, Kaur S, Rajput YS, Kumar R (2009) Activity and thermal stability of indigenous enzymes in cow, buffalo and goat milk. Milchwissenschaft 64(2): 173-175.

65. Salter RS, Fitchen J (2006) Evaluation of a chemiluminescence method for measuring alkaline phosphatase activity in whole milk of multiple species and bovine dairy drinks: Inter laboratory study. J AOAC Int 89(4): 1061-1070.

66. Wernery U, Fischbach S, Johnson B, Jose S (2008) Evaluation of Alkaline phosphatase(ALP), $\gamma$-Glutamyltransferase(GGT) and Lactoperoxidase(LPO) activities for their suitability as markers of camel milk heat inactivation. Milchwissenschaft 63(3): 265-267.

67. Wernery U, Maier U, Johnson B, George RM, Braun F (2006) Comparative study on different enzymes evaluating heat treatment of dromedary milk. Milchwissenschaft 61(1): 281-285.

68. Kwee WS (1985) An improved Aschaffenburg and mullen alkaline phosphatase test for coloured milk products. Aust J Dairytech nol 40: 27-30.

69. Shakeel Ur Rehman, Farkye NY, Yim B (2006) A preliminary study on the role of alkaline phosphatase in cheese ripening. Int Dairy J 16(6): 697-700.

70. Battistotti BE, Brambilla F, Cappa, G Ferrandi (1997) Alkaline phosphatase in milk and ripened cheeses. Sci Tecn Latt Cas 48: 157-162.

71. Pratt Lowe EL, Geiger RM, Richardson TRM (1988) Heat resistance of alkaline phosphatase produced by microorganisms isolated from California Mexican style cheeses. J Dairy Sci 71(1): 17-23.

72. Freeman TR, JL Bucy, AW Rudnick, WF Lewallen (1968) Survey of reactivation of butter. J Dairy Sci 51: 1875-1876.

73. Karmas R, DH Kleyn (1990) Determination and interpretation of alkaline phosphatase activity in experimental and commercial butters. J Dairy Sci 73(3): 584-589.

74. Hahn AJ, PH Tracy (1939) Determining the efficiency of ice cream mix pasteurization through the use of the phosphatase test. J Dairy Sci 22(4): 219-227.

75. Peereboom CJW (1966) Studies on alkaline milk phosphatase I. Nonidentity of rawand reactivated alkaline phosphatase from cream. Neth Milk Dairy J 20: 113-122.

76. Peereboom CJW (1968) Studies on alkaline milk phosphatase II. Occurrence of various phosphatase isoenzymes in dairy products. Neth Milk Dairy J 22: 138-152.

77. Peereboom CJW (1969) Theory on there naturation of alkaline milk phosphatase from pasteurized cream. Milchwissenschaft 24: 266-269.

78. Wright RC, Tramer J (1953) Reactivation of milk phosphatase following heat treatment I. J Dairy Res 20(2): 177-188.

79. Lyster RLJ, RA schaffen burg (1962) The reactivation of milk alkaline phosphatase after heat treatment. J Dairy Res 29(1): 21-35. 
80. Richardson LA, Mc Farren EF, Campbell JE (1964) Dynamic state of milk : Phosphatase reactivation. J Dairy Sci 47: 205-210.

81. Linden G, DT Chappelet-Tordo, M Lazdunski (1977) Milk alkaline phosphatase simulation by $\mathrm{Mg}_{2+}$ and properties of $\mathrm{Mg}^{2+}$ site. Biochim Biophys Acta 483(1): 100-106.

82. Gallusser A, KG Bergner (1981) Reactivation of alkaline phosphatase in UHT milk, depending on its oxygen content. Deut Lebensm Rundsch 77: 441-444.

83. Sharma SK, Sehgal N, Kumar A (2003) Dry-reagent strips for testing milk pasteurization. Lebensm Wiss Technol 36: 567-571.

84. Martin DW, Linxweiler D, Tanzer R, Vormbrock R, Olt C, et al. (2005) Use of the Reflectoquant ${ }^{\circledR}$ rapid tests for determination of thermal in activation of the indigenous milk enzymes lipase, alkaline phosphatase and lactoperoxidase. Deut Lebensm Rundsch 101(7): 281-286.

85. Serra B, Morales MD, Reviejo AJ, Hall EH, Pingarron JM (2005) Rapid and highly sensitive electrochemical determination of alkaline phosphatase using a composite tyrosinase biosensor. Anal Biochem 336(2): 289-294.

86. Hassan SSM, HEM Sayour, AH Kamel (2009) A simple potentiometric method for determination of acid and alkaline phosphatase enzymes in biological fluids and dairy products using a nitrophenyl phosphate plastic membrane sensor. Anal Chim Acta 640(2): 75-81.

87. Rocco RM (1990) Fluorometric determination of alkaline phosphatase in fluid dairy products: Collaborative study. J Assoc off Anal Chem 73(6): 842-849.
88. Caulfield WJ, WH Martin (1939) Certain factors affecting the phosphatase test when applied to icecream. J Dairy Sci 22(4): 261-270.

89. (2007) DHHS-FDA. Grade "A" Pasteurized Milk Ordinance. US Department of Health and Human Services, US Food and Drug Administration Washington DC.

90. International Dairy Federation (1999) Milk and milk based drinks. Determination of alkaline phosphatase activity using a fluorimetric method. IDF-Standard 155A: 3 International Dairy Federation, Brussels, Belgium.

91. Mc Kellar RC, H Cholette, DB Emmons (1988) Modification of the alkaline-phosphatas eassay for butter Can. Inst Food Sci Technol J 21: 97-101.

92. Mc Kellar RC, H Cholette, DB Emmons (1989) Alkaline-phosphatase in butter. Dairy Ind Int 54: 33-34.

93. Murthy GK, Peeler JT (1979) Rapid methods for differentiating reactivated from residual phosphatase in milk and cream: Collaborative study. J Assoc off Anal Chem 62(4): 822-827.

94. Schlimme E, Kiesner C, Lorenzen PC, Martin D (1998) Influence of heat treatment of milk on the activities of the indigenous milk enzymes alkaline phosphatase and adenosine deaminase. Bull Int Dairy Fed 332: 25-31.
This work is licensed under Creative Commons Attribution 4.0 License

Submission Link:

Submit Article

DOI: $10.32474 / C D V S .2018 .01 .000113$

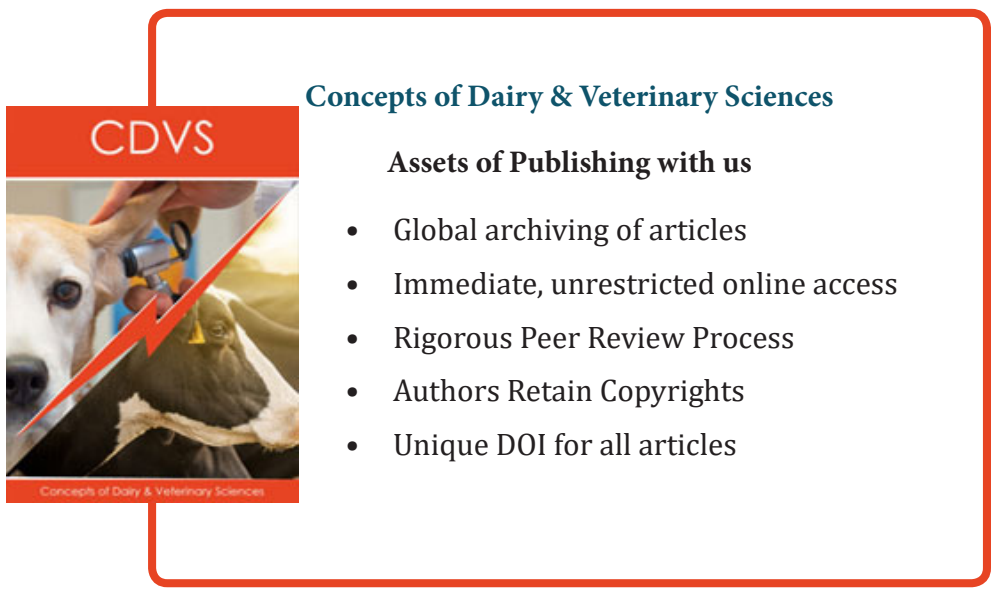

